\title{
ANUNCIAÇÃo E INSURREIÇÃO DA DIFERENÇA SURDA: CONTRA-AçÕES NA BIOPOLÍTICA DA EDUCAÇÃo BILÍNGUE
}

\author{
Alexandre Filordi de Carvalho ${ }^{1}$ \\ Universidade Federal de São Paulo - UNIFESPI \\ Vanessa Regina de Oliveira Martins ${ }^{2}$ \\ Universidade Federal de São Carlos - UFSCar ${ }^{\mathrm{II}}$
}

\section{Resumo}

No campo da surdez, sobretudo na visada antropológica, há uma constante luta dos movimentos surdos pela desvinculação da pessoa surda dos discursos da deficiência. Esse processo ocorre ao afirmar ser a surdez não uma condição de ineficiência corporal, mas uma relação outra do corpo surdo, conferida pela diferença linguística, efeito, exatamente, da não audição. É pela falta orgânica que se constrói a singularidade de uma experiência linguística distinta das pessoas que ouvem. Apesar de uma demanda por afirmar a surdez pelo viés da diferença e da singularidade ainda persiste uma discursividade que indica a experiência da surdez ao corpo deficiente, pautando-se pela concepção patológica. Na sociedade atual, a norma é sem dúvida estratégia voraz para a classificação, a nomeação, o agrupamento e a representação que reduz toda diferença numa base que pretende ser igualitária: ao incluir, exclui inúmeras singularidades, pois trabalha pela homogeneidade. Os surdos são alvo de captura de um saber normativo proposto pela lógica da escola e da sociedade inclusiva, funcionando pela ação noso-política que os classifica por decibéis, pela deficiência, pela falta de língua. Neste artigo, objetiva-se apontar os mecanismos biopolíticos de ajustes do corpo surdo sob a demanda do padrão da escola inclusiva. Problematiza-se: qual a surdez se permite vivenciar na escola inclusiva? Há espaço para a formação-surda? Como manter a singularidade surda quando se propõe um modelo único de funcionamento? Embora a língua de sinais tenha reconhecimento legal e uma maior visibilidade social há processos capilares de captura que diluem ou estriam os diferentes usos desta língua pelos surdos. A promoção de uma escola outra, heterotópica, sobrevive ou resiste na insurreição de novos saberes e forças surdas que reivindicam outras formas de vida. Na constante refacção dos conceitos gastos para a palavra inclusão, por exemplo, pela reconfiguração do espaço comum escolar transgredindo-o em outros modos de funcionamento.

Palavras-chave: biopolítica; educação de surdos; educação bilíngue; insurreição.

\section{ANNUNCIATION AND INSURRECTION OF THE DEAF DIFFERENCE: COUNTER-ACTIONS IN THE BIOPOLITICS OF BILINGUAL EDUCATION}

\begin{abstract}
In the field of deafness, especially within an anthropological view, there is a constant fight of the deaf movements to untying deaf persons from discourses of disability. This process occurs in affirming that deafness is not a body's inefficiency condition, but a distinct relationship of the deaf body, given by the linguistic difference, precisely, an effect of not hearing. In the present society, the norm is an undoubtedly voracious strategy aiming the classification, nomination, gathering and
\end{abstract}

\footnotetext{
1 E-mail: afilordi@gmail.com

2 E-mail: vanymartins@hotmail.com
} 
representation that reduces any differences in the name of an intended equality: by including, it excludes many singularities, because it favors the homogeneity. Deaf people become targets of a normative knowledge proposed by the logic of school and inclusive society through the noso-political action that ranked them by decibels, disability and lack of language. In this article, we aim to point out the biopolitic mechanisms of the deaf body adjustments under the demand of the standard of inclusive school. It problematizes: what kind of deafness is allowed to experience in an inclusive school? Is there room for a deaf training? How to keep the deaf singularity when proposing a single model functioning? Although sign language has legal recognition and greater social visibility there are some processes of capture that dilute or striate the different uses of this language by deaf people. The promotion of a heterotopic school survives or resists in the insurrection of new knowledge and deaf forces which claim for other forms of life by the constant retaking of shabbyconcepts for the word inclusion, for example, by reconfiguring the school common area and transgressing it in other operating modes.

Keywords: biopolitcs ; education of the deaf ; bilingual education ; insurrection.

\section{ANUNCIACIÓN Y INSURRECCIÓN DE LA DIFERENCIA SORDA: CONTRA-ACCIONES EN LA BIOPOLÍTICA DE LA EDUCACIÓN BILINGÜE}

\section{Resumen}

En el campo de la sordera, especialmente desde la vista antropológica, hay una lucha constante de los movimientos sordos para desvincular a dicha persona de los discursos de discapacidad. Este proceso ocurre afirmando que la sordera no es una condición de deficiencia, sino una relación otra del cuerpo sordo, dada la diferencia lingüística, precisamente en efecto de no oír. Es por la falta orgánica que se construye la singularidad de una experiencia lingüística distinta de las personas que oyen. A pesar de una demanda por afirmar al estado de sordera como una diferencia y singularidad, todavía persiste un discurso que indica a la experiencia de la sordera como un cuerpo discapacitado, guiado por la concepción patológica. En la sociedad actual, la norma es, sin duda, la estrategia voraz por la clasificación, nomenclatura, la agrupación y representación que reduce una diferencia en una base que está destinada a ser igual: para incluir, excluir a muchas singularidades, funcionando en base a la homogeneidad. Los sordos son objetivo de un la captura de un saber normativo propuesto por la lógica de escuela y de la sociedad inclusiva, mediante el trabajo de acción noso-política que los ordena por decibeles, deficiencia y por la falta de lenguaje. Este artículo tiene como objetivo señalar los mecanismos biopolíticos de ajuste del cuerpo sordo ante la demanda del padrón de escuela inclusiva. La problemática: ¿Qué se le permite experimentar a la sordera en la escuela inclusiva? ¿Hay espacio para la formación de una persona sorda? ¿Cómo mantener la singularidad de la persona sorda, al proponer un modelo único de funcionamiento? Aunque el lenguaje de señas tiene reconocimiento legal y una mayor visibilidad social, existen procesos de captura que diluyen y señalan los diferentes usos de la lengua por los sordos. La promoción de una escuela diferente, hetero-tópica, sobrevive o resiste en la insurrección de nuevos saberes y fuerzas sordas, que reivindican otras formas de vida. En el constante rehacer de conceptos gastados por la palabra inclusión, por ejemplo, por la reconfiguración del espacio común escolar transgrediéndolo en otros modos de funcionamiento.

Palabras clave: biopolítica; educación de sordos; educación bilíngue; insurrección. 


\title{
ANUNCIAÇÃO E INSURREIÇÃO DA DIFERENÇA SURDA: CONTRA-AÇÕES NA BIOPOLÍTICA DA EDUCAÇÃO BILÍNGUE
}

\section{Introdução}

\begin{abstract}
E quem se envergonha, a cada milionésimo mudo de sílaba, e inextinguível infinito de remorsos se entranhando, de mordida em mordida, de ter que ouvir, de ter que dizer, aquém do menor murmúrio, tantas mentiras, tantas vezes a mesma mentira e mentirosamente desmedida [...]
\end{abstract}

(BECKETT, 2015, p.59).

O presente trabalho problematiza a surdez como campo de saber outro que se volta para questionar as produções de verdades atreladas em cada forma de condução do sujeito surdo. A intenção é a de promover uma análise nas abordagens inclusivas que englobam, notadamente no registro escolar, os modos de vidas dos sujeitos surdos, uma vez que eles são afetados por polícias públicas, dentre elas, as que se destinam ao campo da educação.

Para tanto, levaremos em consideração a relação que a surdez possui com o que Foucault (1979) denominou de governamento ou governamentalidade. Tratase de investigar a surdez sob a conjuntura de uma tecnologia de poder que se aplica à vida por meio da arte de governar os vivos, instaurada pelas estratégias noso-políticas geridas pelas classificações que produzem agrupamentos e facilitam as práticas de governamento de grupos populacionais. De modo bem amplo, para Foucault, a questão das formas de governo se dispuseram com grande vigor a partir do momento em que grupos inteiros de indivíduos passaram a ser coligidos em populações para efeito de uma administração racionalizada de suas vidas: “como governar crianças, como governar os pobres e os pedintes, como governar a família, a casa, como governar exércitos, como governar diferentes grupos, cidades, estados, como governar o próprio corpo, como governar a própria mente" (FOUCAULT, 1996, p. 384), e por que não, como governar os surdos?

Para Carvalho (2012), na tradição ocidental, a escola se mantém como local que forma a conduta dos alunos, mantendo-se atrelada a uma série de regulamentos, diretrizes que fundamentam certo currículo e saberes que norteiam padrões de comportamento. Dessa maneira, a escola opera assegurando a validade 
de uma verdade em detrimento de outras. Desmantelar o jogo da "singular inflação normativa implicada na própria norma" (CARVALHO, 2012, p.124) escolar não é nada fácil. O problema que se coloca para a inflação normativa é o de sua relação com os tipos de direcionamentos e de práticas hauridos da norma, já que ela produz uma média e um suposto modelo a ser alcançado. Com efeito, sempre estarão em causa escolhas necessárias numa arena de disputas teóricas que moldam e engendram os sujeitos envolvidos nesta (forma)(ta)ação.

Com os sujeitos surdos não é diferente, senão mais perverso, pois as tecnologias de poder voltadas para o governamento deles se dispõem de modo mais tenso nas políticas inclusivas. Tal tensão se encontra, de um lado, nas disputas pela construção de uma escola bilíngue e, de outro lado, na manutenção do discurso desgastado e viciado sobre a inclusão baseada no imperativo da convivência ou no discurso da diversidade. Para nós, é fundamental tornar potente a reflexão da ação biopolítica na vida dos surdos, sobretudo indagando pelas ações que são extraídas de princípios políticos que geram práticas idealizadas para o surdo, muitas delas ignorando a própria anunciação surda empreendida por seus sujeitos.

Ora, muitas ações se consolidam nos currículos escolares, em nome da escolha linguística disseminada à população surda, promovendo uma sutil exclusão, tal como na política racial analisada por Foucault (1999), por "fazer morrer" a formação surda tão almejada pelas comunidades surdas. Nos termos de Carvalho (2012), sustenta-se, assim, a exclusão ou a inclusão-excludente, mesmo dentro das escolas inclusivas, sobretudo quando não se traz a língua de sinais para as salas de aula, ainda que o surdo esteja ali "inserido". Se a língua de sinais não se coloca na posição de possibilidade de enunciar conteúdos, o apagamento da surdez é inevitável, ou melhor, promove-se o silenciamento do surdo. E mais ainda, impossibilita-se a não abertura para a construção de uma escola na qual os surdos, aqueles que reivindicam o uso da língua brasileira de sinais (Libras)3, possam compor "voz", pensando na construção de uma escola outra. O trabalho

\footnotetext{
${ }^{3}$ Doravante Libras para referir-se à Língua Brasileira de sinais.
} 
de Carvalho (2012) pode ser articulado nesta temática anunciada ao revelar a produção normativa e a sua proliferação de mesmidades no campo da educação, ainda que pense no propósito geral escolar e não na especificidade da educação de surdos. Consideramos que tais problematizações são pertinentes para o que trataremos sobre a educação bilíngue e a insurreição surda no momento atual em que se reivindica a entrada da Libras de modo efetivo no cotidiano escolar e não na instrumentalidade que mascara e apaga a surdez na estratégia cruel de "fazer viver" um tipo de experiência, "deixando morrer" 4 tantas outras:

\begin{abstract}
Na mesma proporção, é assim que o campo da educação, inevitavelmente relacionada à história de suas empiricidades, alojará na escola toda forma de saber possível, como condição normativa para se educar, e desqualificará outros tipos de saberes. As constantes reformas empreendidas neste amplo domínio, das políticas às pedagógicas, testemunham a dinâmica reguladora do saber que avaliza como caduca uma prática e a outra como inovadora, desqualificando aquela e enaltecendo esta. Educar torna-se, com efeito, um ato condicionado às seleções de sabres que chancelarão o seu ato, ao mesmo tempo, como adequado e pertinente ou como inadequado, ultrapassado e errôneo (CARVALHO, 2012, p.134).
\end{abstract}

Dito isso, consideramos que uma das pretensões deste artigo é a de problematizar o lugar da Libras e do surdo quer seja numa escola bilíngue, quer seja na escola inclusiva, mesmo a despeito do que o termo inclusão pode aferir de maneira viciada. De todo modo, a formação-surda é convocada a ser pensada dentro da própria enunciação surda e de suas insurreições contra as capturas biopolitizantes da surdez. Para tanto, sustentamos ser necessário pensar um tipo de desestabilização na atual política bilíngue promovida por agenciamentos biopolíticos, desestabilização arregimentada pelas insurreições surdas, como veremos. Não sem sentido, ao longo do artigo, buscaremos mostrar que uma das estratégias deste poder biopolitizado é o de manter o imaginário do bem comum e da melhoria da "raça surda" pelo empoderamento da língua portuguesa, uma ação justificada como bem comum para esta população e que se realiza no

\footnotetext{
${ }^{4} \mathrm{O}$ conceito de "fazer viver" e "deixar morrer" é trabalhado por Foucault na aula de 17 de março de 1976 quando aponta o deslocamento da ação do poder soberano que agia de forma a "fazer morrer" e "deixar viver". Esta mudança se dá na análise do poder disciplinar conferido nos corpos individuais e posteriormente com a ação da biopolítica, e do biopoder, no racismo de estado isso se amplia à população. Esta temática será melhor trabalhada na parte do texto voltada à biopolítica $\mathrm{e}$ às questões da surdez.
} 
anunciação e insurreição da diferença surda: contra-ações na biopolítica da educação bilíngue

aparelho escolar. Discurso sutil que mantém a centralidade da língua portuguesa no ensino dos surdos fazendo do bilinguismo não a entrada principal de duas línguas na escola, mas a manutenção hegemônica da língua portuguesa (LODI, 2013). Nosso problema central é o de pensar em como fazer valer as vozes surdas deslocando do saber que as prende ali, na seleção de saberes escolares? (CARVALHO, 2012). Mas também o de investigar como possibilitar viver a singularidade surda, sem nos prender a um discurso gerido para uma massa homogênea? Como valorizar a formação surda pela Libras?

No primeiro momento deste artigo abordaremos a surdez como campo de saber, produção de verdades e constituição de subjetividades surdas, apostando na necessidade de revisão das dualidades existenciais: patológico ou cultural. Ao sair desta lógica dual favorecemos a singularidade de uma formação experiencial sem um modelo único. Num segundo momento, travaremos um diálogo com as questões da biopolítica e de seus agenciamentos na escola, apontando as tensões na produção de políticas bilíngues. Faremos esse diálogo por meio do filme "Nell" (APTED, 1994), e chamá-lo-emos aqui de: o caso Nell e suas articulações na educação de surdos. Por fim, traremos as insurreições surdas e as resistências para a permanência da singularidade surda, em suas multiplicidades, na contaminação que produzem na língua portuguesa, no ensino, na docência, considerando a perspectiva do micro, ou seja, do cotidiano da escola.

\section{Surdez como campo de saber: discursos sobre a experiência surda e seus atravessamentos na escola}

Para poder escutar eu olho! ${ }^{5}$

(FRANÇA, 1990)

\footnotetext{
${ }^{5}$ Esse é o título de uma das cenas da obra "Cenas Surdas: os surdos terão lugar no coração do mundo" (LUZ, 2013, p. 100). Na obra o autor destaca algumas cenas, como dispositivo metodológico de análise da teoria proposta e defende a necessidade de aparição dos surdos no mundo e por meio da língua de sinais. Nesta cena específica é descrito uma conversa entre uma mãe e seu filho surdo. No primeiro momento o menino ensina sinais para a mãe e depois ele terá que tentar mostrar sua capacidade comunicativa repetindo frases em francês. Quando percebe que o menino foca os olhos na boca a mãe sente-se trapaceada, então ele declara que para "ouvir", "olha". Essa escuta que se faz pela audição e ressignificação do "normal" dos sentidos é tema instigante para o presente trabalho.
} 
Há inúmeras formas de viver a experiência da surdez. No que tange aos discursos científicos sobre as práticas corporais e às estratégias de individualização e ao disciplinamento do surdo, estas formas de vidas têm sido narradas em pelo menos dois campos distintos e contraditórios entre si. A primeira narrativa insere a surdez nos discursos da deficiência, na perspectiva clínica, na qual há a patologização do outro (surdo) que vive a negatividade da falta orgânica e carece de reparo por meio de técnicas ortopédicas e corretivas: próteses auditivas, implantes cocleares, treinamentos orofaciais, entre outras formas de correção do corpo e da forma de vida de ser e se fazer surdo (SOUZA, 2006; LOPES, 2007; MARTINS, 2008, 2013a; REZENDE, 2010). Em relação aos produtos da perspectiva clínica, Rezende (2010) afirma que as tecnologias médicas têm produzido uma invasão no modo de vida do surdo e produzido subjetividades surdas que visam o adestramento de corpos. Sendo surda, a autora apresenta "uma pesquisa motivada pela resistência da pesquisadora com relação ao campo 'implante coclear', que tem o efeito de normalizar os sujeitos surdos, subalternizando a língua de sinais e a cultura surda" (REZENDE, 2010, p. 17 aspas da autora).

A segunda perspectiva anuncia a surdez como experiência visual inserindo o surdo no discurso antropológico e cultural. É a falta de audição que promove outra forma singular de experienciar o mundo e se fazer sujeito. Em tal perspectiva, está implícita a positividade da surdez pelo uso de outra forma de comunicação, a língua de sinais. A questão da língua está colada às formas e às manifestações identitárias e culturais. Segundo Strobel (2008), as experiências visuais são consideradas como artefatos culturais surdos relacionados às questões particulares de vivências dos surdos no contato com um universo sonoro e com suas ressignificações, compartilhadas nas comunidades surdas. "Os sujeitos surdos, com a sua ausência de audição e do som, percebem o mundo através de seus olhos, tudo o que ocorre ao redor dele [...]" (STROBEL, 2008, p. 39). Portanto, neste viés, não estamos mais diante de uma necessidade de reparo do corpo individual surdo, mas em outra construção política que insere as demandas dessa comunidade minoritária, sejam elas: a veiculação da língua de sinais no Brasil, e 
ainda, a presença de marcadores culturais, reflexo das lutas e da inserção de vozes outrora silenciadas nas comunidades surdas (LOPES, 2007; GESSER, 2009).

Neste sentido, Skliar (2013) atesta tal conjuntura ao apontar para a necessidade de desconstrução das representações fixadas sobre o surdo, a surdez e as práticas corporais possíveis, ao desnudar a proposta de saída dos estudos surdos, em sua perspectiva escolar, antes vinculado aos discursos sobre a surdez postos no campo da educação especial. Educação que, por sua vez, pensa as adequações e as adaptações para o público com deficiência. Não sem sentido, com respeito à educação especial, o autor argumenta o seguinte:

[...] nesse contexto não são reconhecidos aos surdos - como também aos cegos, aos deficientes mentais, etc. - os múltiplos recortes de identidade, cultura, comunidade, etnia, etc. Os surdos são definidos somente a partir de supostos traços negativos, percebidos como exemplos de um desvio de normalidade, no pior dos casos, ou de uma certa diversidade, no melhor dos casos. Essa última questão pode abrir a discussão sobre a definição da surdez como diferença política (SKLIAR, 2013, pp. 12-13).

A educação especial assim pensada segue a lógica noso-política pela classificação do que é a surdez, de modo geral, por meio de limites auditivos. A perspectiva tomada é a de agrupar todas as deficiências como caso, ou problema para ser gerido por este novo campo de saber. Define-se a noso-política como a arte de governar os homens pela classificação, uma vez que em nossa sociedade foi introduzida irremediavelmente às diferenciações entre os indivíduos para efeitos classificatórios (CARVALHO, 2015). Apenas assim foi possível emergir governos múltiplos com intenções das mais variadas possíveis. Mas todas elas respaldadas pela classificação noso-politizada dos modos de vida, ensejando, assim, séries distintas de ordenamento dos sujeitos, pareando-os aos seus respectivos processos de governamento. Com efeito, tanto a definição do sujeito surdo, neste caso, quanto a forma pela qual ele é conduzido e tratado na rubrica do governamento faz alusão à sua destinação final na noso-política. Por isto mesmo, a lógica da classificação é mantida nos discursos da educação especial pela negatividade, acionando reparos por meio da inclusão de surdos nas escolas comuns e forçando-os a aí se adequarem. 
Conforme aponta Lodi (2013), é justamente pelas diferentes formas de se entender o conceito de inclusão que os movimentos surdos enfrentam constantemente resistências na construção de políticas de aberturas de escolas bilíngues de surdos, ou de salas bilíngues em escolas inclusivas; uma vez que se toma, nas políticas voltadas à educação especial na ação da educação inclusiva, a inclusão como espaços de trocas sociais entre os diferentes e os ditos "normais". A reivindicação dos surdos está na construção de uma inclusão que qualifique suas diferenças e promova, não meras trocas sociais, mas construções de conhecimentos pareados que os coloquem em condição de inclusão social efetiva. Portanto, nas políticas vigentes da educação especial a inclusão é dada como participação de surdos nas escolas comuns; para o Decreto 5.626/05, resultado de lutas sociais em favor da visibilidade das minorias, a inclusão se dá na presença da Libras como língua de instrução escolar. Para tanto, pressupõe-se mudanças radicais na escola.

\begin{abstract}
Assim, de forma contrária ao disposto no Decreto, a Política, ao orientar sobre a educação de alunos surdos, não deixa claro qual língua deverá ser utilizada pelo professor nas salas de aula inclusivas (língua portuguesa ou Libras), desconsiderando o fato de ser impossível o uso de ambas concomitantemente. Infere-se, pelo discurso utilizado, que a língua portuguesa em sua modalidade oral seja aquela utilizada pelo professor, a língua de interlocução nas salas de aula, logo aquela responsável pela mediação dos processos de ensino e de aprendizagem dos alunos (LODI, 2013, p. 55 - grifo da autora) ${ }^{6}$
\end{abstract}

Diante das conjunturas políticas, seja dentro da educação especial, ou nos documentos sobre a acessibilidade do surdo na entrada da Libras, e ainda nas pesquisas sobre a surdez, há uma necessidade de classificação sobre as possibilidades de ser e como se anunciar surdo, aspectos que nos chamam a atenção. Isso porque conferem verdades para a educação e o governo destes sujeitos na escola. Se em um primeiro momento a nomeação deficiente tende a estar colada à perspectiva clínica para, em seguida, especificamente ao surdo, passar a considerá-lo como um ser cultural usuário de uma língua visual-gestual, algumas questões emergem: em que medida é possível abranger as múltiplas

\footnotetext{
${ }^{6}$ A autora usa o termo Política para se referir às ações da educação especial no documento norteador Política Nacional de Educação Especial na Perspectiva da Educação Inclusiva. Promove uma análise interessante dos dois documentos a Política nacional e o Decreto 5.626/05 apresentando as disparidades no conceito de inclusão e de educação bilíngue.
} 
anunciação e insurreição da diferença surda: contra-ações na biopolítica da educação bilíngue

formas de existências surdas, sem podar as singularidades que querem se expressar? Ou seja, sem as classificar? Notemos que em ambos os discursos sobre a surdez estão implicadas formas esperadas de vida para o outro. Em termos biológicos ou clínicos, tem-se formulado o modo e os efeitos que se esperam sobre o reparo do corpo deficiente, e o quanto as tecnologias de ajustes tornam essa vida mais próxima do ápice da curvatura, ou do que se forjou como "normal", sendo uma vida mais útil e mais produtiva. Em contrapartida, no âmbito do saber cultural pode-se fazer o mesmo movimento de normação quando se condiciona formas (únicas) possíveis de existências surdas: aqueles que fazem bom uso da Libras, numa padronização linguística, envolvendo processos de disputa na afirmação do uso certo da língua, por vezes baseando-se de um purismo linguístico essencialista, e, consequentemente, aqueles que se reconhecem como sujeitos partilhadores de uma identidade em comum, a surda; ou aqueles que vivem intensamente na comunidade surda, e lutam pelos ideais políticos deste grupo.

Aqui não está em pauta o certo e o errado de cada saber. Ao se configurarem como saber, entretanto, eles se associam às verdades e às condutas esperadas ao outro (surdo), a um modo de subjetivação que configuram práticas. Maher (2007) alerta para os cuidados com relação a uma visão essencialista de cultura, guardando um purismo, ou ainda, a busca por uma unidade linguística, unidade identitária. Tais cuidados são imprescindíveis para não se radicalizar as experiências culturais e outra vez apagar as diferenças, ou oferecer opressões linguísticas de outras medidas (GESSER, 2006, 2009, MARTINS, 2013b). Nessa mesma linha, Bastos (2013, p. 17 - aspas da autora) defende que “o mundo é habitado por 'surdos personalizados' que fazem e refazem o cotidiano cultural e não podem ser reduzidos à uniformização sugerida pela categoria 'cultura surda', em oposição aos ouvintes". Bastos ainda alerta para a necessidade da ampliação conceitual sobre cultura e para a pluralidade que a surdez evoca em cada sujeito surdo, não negando a especificidade visual, a qual nomeia por experiências culturais - no plural. 
Com relação a essas distinções e formulações de saberes, embasados pelos constructos foucaultianos, Morgenstern e Witchs (2015) produzem duas formas de pensar a produção de subjetividades surdas no decorrer da história, no campo da surdez, e analisam os discursos na atualidade que permitem verificar a emergência dessas relações subjetivas, sendo elas: subjetividades deficientes, ou subjetividades plurais; que retomam a negatividade e a positividade dada às experiências.

Especificamente, identificou-se que uma forte ênfase em subjetividades deficientes pauta as formas de ser surdo na metade do século, enquanto que, na outra metade, a ênfase se desloca para a produção de subjetividades plurais, marcadas por uma forma culturalista de ser surdo. Mesmo que essas formas subjetivas sejam capturadas por mecanismos de poder e ressignificadas no registro de novas normalizações, fica a possibilidade de haver espaço para a criação de outros modos de existência (MORGENSTERN; WITCHS, 2015, p. 1 - grifos dos autores).

Para desenvolver tal argumentação, os autores usaram documentos legais contendo discursos de surdos referentes a surdez e a relação de práticas de disciplinamentos pelo olhar biológico e pela vertente cultural. Anunciações distintas conduzem formas de vida também diversas: “a surdez se constitui como uma forma de existir no entrecruzamento de saber, poder e ética" (MORGENSTERN; WITCHS, 2015, p. 3). A produção de subjetividades só se afirma pelas experiências possíveis. Para a conceitualização de experiências usa-se aqui, como no artigo apresentado por Morgenstern e Witchs (2015), a noção de foco ou matriz de experiência, desenvolvida por Michel Foucault (2010, 2011a, 2011b). Para o filósofo francês, toda experiência emerge do entrelaçamento de dispositivos que, em distintas frentes e em amplas atuações, interpenetram, ao mesmo tempo que consubstanciam, as condições histórias responsáveis pelo nascimento de uma experiência. Sexualidade, loucura, anormalidade, por exemplo, são experiências variáveis conforme os intensificadores discursivos e práticos arranjados em um feixe de dispositivo. Toda experiência, assim, é imanente ao seu campo histórico de emersão e é, ao mesmo tempo, a visível materialidade virtualizada em ação, em prática, em discursividades igualmente históricas cujos acentos variam conforme "o eixo da formação dos saberes, o eixo 
da normatividade dos comportamentos, e enfim, o eixo da constituição dos modos de ser do sujeito" (FOUCAULT, 2010, p. 41).

Levando a proposta de Foucault em consideração, é possível sustentar que a surdez é derivada de alguns condicionantes advindos de certos focos de experiência. Por conseguinte, a surdez é experiência que reduplica uma matriz de saber, uma outra de comportamento e ainda mais outra de subjetivação surda. Se é verdadeiro que foi a partir da formação de um saber clínico e científico sobre a surdez que se aplicaram técnicas de disciplinamento por meio de uma normativa, isto é, técnicas visando a produção de um comportamento surdo, também é verdadeiro que, partindo do comportamento surdo que se estabilizou sob vários efeitos dos dispositivos de governamento da surdez, haveríamos de chegar aos fundamentos dos saberes que consolidaram o mesmo jogo matricial da emersão de um experiência surda em detrimento de outra. Quer dizer, de um conjunto de saberes se fundou a analítica do tipo surdo. Este, por sua vez, vê-se reduplicado naquela, num circuito infinito de acomodação. Mas se os saberes tivessem concebido a surdez em outra perspectiva certamente a sua tipologia seria de outra ordem. Por isso mesmo, podemos pensar que tais técnicas conduziram e conduzem modos de comportamentos, resguardando-os em saberes capazes de justificar ao sujeito surdo a imposição da leitura labial ou do aprender a oralidade; ou ainda, a da obrigatoriedade de se inserir no universo de quem ouve, em detrimento de sua própria singularidade e valorização cultural. Como se vê, nenhum eixo de saber se orienta sem a implicação da normatividade comportamental e da produção positiva de experiências subjetivas que daí se extraem.

Ora, cada deslocamento de perspectiva dentro de tal conjuntura pressupõe a convocação de outros saberes em movimento que, por sua vez, induzem normativas e produzem modos de vida igualmente outros. Quebrar os fios das mesmas amarras das matrizes de experiência como a da surdez implica indagar pelos componentes históricos responsáveis por localizar o sujeito surdo apenas na circunscrição a um campo de saber com as suas verdades e fronteiras para os modos de viver (FOUCAULT, 2010). Não é à toa que a perspectiva cultural abre 
para a surdez o convite para que ela se prolifere em modos de ser com outras possibilidades, afim de que os surdos possam constituir suas identidades se valendo da língua de sinais em suas múltiplas vertentes e formas, além de coproduzirem a própria cultura surda, de estar na comunidade, de viver sob os seus referentes sociais, devendo ter acesso e direito a eles, conforme as demandas singulares do modo de ser surdo. Mas se tomamos como parâmetro a escola o que observamos, contudo, é um tipo de saber monolinguístico, calcado em empirias monoideístas, a destacar o lugar da surdez sob a rubrica da abordagem clínica. Mesmo que alguns aspectos da questão cultural estejam presentes na escola, como a invocação ao respeito pelo surdo, a tentativa de a escola se empenhar em gestar condições para a formação do aluno surdo por intermédio da Libras, ainda assim, prevalece certo apagamento da surdez por intermédio do discurso e da prática da reabilitação do surdo pela majoração da lógica de uma educação para quem ouve.

Sob tal dimensão, não pretendemos narrar a experiência surda pela negatividade do corpo, nem tão pouco na polaridade extrema como igualdade homogênea, sendo só positividade vivenciada pela cultura visual expressada na forma de uma unidade identitária que faz do sujeito refém do certo da língua e do certo da identidade como blocos fechados e prontos, bastando serem colocados em si e usados (MAHER, 2007). Afirmamos, contudo, ser a surdez, sim, experiência corporal que toma a visão como marcador primordial e produtor de cultura, pois cada corpo surdo limita-se às suas significações, aos seus processos possíveis e singulares de vida surda. E afirmar a diferença na direção de sua produção é necessário para não se cair no discurso da igualdade que gera e mantém o apagamento das diferenças.

Ao apresentar as problematizações e as lutas surdas pelos seus direitos linguísticos, bem como as singularidades culturais presentes nos discursos antropológicos, queremos desarticular a ideia comum da apologia discursiva sobre a inclusão: "somos todos iguais". Não somos todos iguais nem quando usamos a suposta 'mesma' língua. Trata-se de pensar a vida para além da forma, ou num modelo padronizador, ampliando modos de ser que não precisam e não devem ser tomados sob uma única perspectiva. Isso envolve produzir múltiplos 
saberes e modos de "degustar" as suas passagens e paragens na singularidade de cada corpo surdo. Não há igual uso da língua, do corpo, da aprendizagem. Não há uma ou duas formas de ser surdo. É nesse intuito que propomos considerar a retomada da experiência surda para então podermos pensar a educação bilíngue que traz a Libras para o bojo das discussões, mas que sabe da tensão de criar políticas populacionais mantendo a singularidade: as resistências sempre aparecerão. Neste sentido, concebemos a vida surda não como aquela reduzida ao falso discurso do filantropismo capitalista, como aponta Lipovetsky (2005), sob o qual, o surdo tem de fazer por merecer, produzindo conforme "iniciativas eficazes", em nome da hegemonia moralizante fundada "em valores morais comuns, na obra da regeneração dos costumes" (LIPOVETSKY, 2005, p.24). Mas que não seja assim. A vida surda interpõe aos limites comuns do mundo ordinário o seu próprio fracasso, uma vez que a ele assinala que outros sujeitos querem viver, e o são capazes, conforme a consonância de valores idiossincráticos da surdez. E a tudo que se agita demais pelo valor da mais-valia normativa dos modos de viver, por sua gritante ordem por matrizes de experiência, a surdez insiste impor o seu silêncio para que se faça escutada. A sua língua, ao dançar gestualmente, emudece o próprio sentido sonoro da palavra que não possui corpo e não se estende com o corpo. Nesta língua, com este gesto, o surdo ousa resistir, tomando lugar na diferença, incomodando a norma, questionando os padrões escolares, apontando para aquilo que ainda não ousamos compreender, a não ser que abandonemos a voz de nosso próprio saber e de nossas matrizes de experiência.

\section{Biopolitização na escola inclusiva e intsrumentalidade da lingua de sinais}

O país mantém interna e externamente o mito de nação "monolíngue", tornando, assim, invisíveis suas "minorias" linguísticas e socioculturais [...] Nesse contexto é que se instala o prestígio de determinada norma da língua portuguesa e apagamento das línguas nacionais minoritárias (CÉSAR; CAVALCANTI, 2007, p. 50 - aspas do autor). 


\section{O CASO NELL E SUAS ARTICULAÇÕES NA EDUCAÇÃO DE SURDOS?7}

O filme "Nell" (APTED, 1994) retrata a vida da jovem Nell (Jodie Foster). Ela é encontrada em uma casa, na floresta, onde vivia com sua mãe eremita. O médico (Liam Neeson), no filme nomeado por Lovell, que a encontra após a morte da mãe, constata que ela se expressa em um dialeto próprio, evidenciando que até aquele momento ela não havia tido contato com outras pessoas. Intrigado com a descoberta e ao mesmo tempo encantado com o estilo de vida da moça, ele tenta ajudá-la a se integrar na sociedade e reconhece que aquela forma de vida de Nell é legítima e não precisa ser reparada. O médico aprende a se comunicar com Nell. No entanto, o caso chega ao instituto de psicologia que se ocupa do cuidado de doentes mentais. A equipe clínica julga a necessidade de tratamento de Nell e a retirada dela da casa onde vivia. Cativado pelo modo de vida da jovem, Lovell tenta mostrar pelo discurso médico e jurídico a possibilidade que vê na jovem de viver em seu lar, de manter a sua língua e as suas memórias. Embora tendo que argumentar juridicamente em favor da sanidade de Nell, ela é levada a julgamento. Lovell servindo-se de intérprete, facilita a interação e a possibilidade de enunciação de Nell em sua língua. Na audiência, a contra-argumentação dos juristas e da equipe médica geral é a de quel Nell deve ser civilizada e que tem muito a aprender socialmente. Nell, em sua fala interpretada pelo médico, argumenta que aquilo que denunciam ser barbárie não passa de uma diferença de vida e que é nela que quer se manter viva, porque ali se constituiu sujeito. Por fim, Nell argumenta que o que vê na plateia são pessoas que conhecem muita coisa que ela desconhece, mas que não conseguem falar olhando nos olhos, e não é essa vida que ela quer viver.

A epígrafe acima se articula ao caso mencionado. A disputa pela língua que Nell deve falar e a forma como deve viver chamam a atenção e servem de base para as análises que faremos. A necessidade de instrumentos e de saberes médicos para nomear o que "aquela selvagem" tinha em seu corpo defeituoso e incompleto, se autismo, se deficiência intelectual, são temas que percorrem o enredo do filme. Ali aparece com grande evidência a voz jurídica como saber que julga e permite como e onde Nell poderá viver: se em seu espaço isolado, ou na sociedade. Parece-nos que tais cenas se repetem nas práticas concretas, ou com mais precisão, nas matrizes de experiência do campo da surdez. São testemunhas desta coincidência entre ficção e realidade a nomeação e a classificação do grau da surdez pelos matemas dos decibéis; as estratégias que tentam reconciliar o surdo com a sociedade, exigindo dele um esforço sobre-humano para se fazer entendido e reconhecido socialmente; as constantes lutas legais para o surdo poder provar a legitimidade do uso de uma língua que não é a padrão, nem a modalidade mais convencional, ou seja, línguas orais. Nell fala uma língua que não pode ser falada, não tem legitimidade, não é reconhecida. Na mesma proporção, os surdos ferem a escola com seus gestos, falas que não são também reconhecidas, vozes que devem

\footnotetext{
${ }^{7} \mathrm{O}$ resumo do filme Nell é marcado pelas nossas interpretações, enquanto autores deste artigo.
} 
ser interpretadas e aprimoradas pelo uso da língua comum: a língua portuguesa. Mas não nos enganemos, se a classificação funciona no filme como necessidade de diagnosticar "o caso Nell", também impera no espaço escolar e na educação inclusiva, na tarefa de diagnosticar a surdez, apresentando a melhor forma de condução para a aprendizagem voltada ao outro surdo, direcionando-a por meio de uma língua não familiar para os sujeitos, mas língua de conforto para quem pensa as ações. No entanto, a argumentação da educação bilíngue e uma refacção de educação inclusiva pelo uso da Libras, como forma de experiência surda, tem sido debatida academicamente. Como Lovell, no filme, alguns pesquisadores (surdos e ouvintes) ousam enfrentar juristas e instituições, por meio de articulações militantes, num discurso contrário a imposição do ensino certo para o surdo - do modelo único. E como Nell, muitos surdos têm se manifestado em defesa de uma educação pensada por eles, na qual suas demandas possam ser ouvidas com legitimidade.

De todo modo, é incontornável o fato de que ao surdo não é dada a escolha em ser ou não ser bilíngue. Ao ingressar no espaço escolar ele já se depara com a instrução na língua portuguesa. Poucas experiências de projetos espalhados no Brasil desenvolvem ações de uma educação bilíngue na contra-marcha da proposta inclusiva meramente político-legal. Em pesquisa recente, empreendida por um surdo, Carvalho (2016) mostra que a Libras presente no contexto escolar possui tônica meramente instrumental. Neste sentido, ele argumenta: "portanto, a inclusão trata de uma estratégia política de investimento do Estado na regulação de sujeitos 'anormais', no caso desta pesquisa, sujeitos surdos, por meio de práticas de governamento específicas, inclusive sobre a Língua desses sujeitos" (CARVALHO, 2016, p. 59 - aspas do autor).

Ora, para pensar a ação da inclusão e os processos que legitimam seu funcionamento na dificuldade de promoção de outros saberes, faremos um diálogo com o conceito de biopolítica em Michel Foucault. De maneira sucinta, a biopolítica envolve tecnologias de poder voltadas para a gestão e o controle da vida de populações inteiras, regulamentando-a. Por vida entende-se não apenas a condição precípua dos condicionantes biológicos humanos, mas também as 
relações racionalizadas que gerenciam e gestam tais condicionantes: enfermidades, finitudes materiais condicionadas à fome, à sede, aos recursos necessários para se viver com a mínima dignidade. Este patamar da vida, na biopolítica, coincide com os modos de ser que são forjados para populações inteiras. Representa pensar que as opções administrativas e de governamento pelas quais determinado surto de vírus atinge um grupo populacional afeta o modo de ser dos indivíduos implicados na mesma população ${ }^{8}$.

Esta tecnologia de poder se configurou no Ocidente desde o final do século XVIII valendo-se dos corpos disciplinarizados pela sagração do poder disciplinar, responsável por produzir individualidades em série. $\mathrm{Na}$ interpretação de Foucault, a biopolítica amplificou o refinamento das relações de poder a partir do momento que a gestão de populações inteiras endossou o poder dos Estados com o fito de reunir os seus indivíduos em categorias, em classificações, em distribuições hierárquicas úteis às suas estratégias de governamentalidade. Por esta razão, poder disciplinar e poder biopolítico armam-se numa dupla estratégia: para a configuração de qualquer população um foco de experiência teve de ser tratado individualmente em sua produção. Para cada morte individual, por exemplo, há um perfil demográfico coincidente. Faz todo sentido, portanto, Foucault afirmar que a biopolítica envolve "um conjunto de processos como a proporção dos nascimentos e dos óbitos, a taxa de reprodução, a fecundidade de uma população, etc." (FOUCAULT, 1999, p. 289-290). Por isso mesmo,

Uma tecnologia de poder que não exclui a primeira, que não exclui a técnica disciplinar, mas que a embute, a integra, que a modifica parcialmente, e que, sobretudo, vai utilizá-la implantando-se de certo modo nela, e incrustando-se efetivamente graças a essa técnica disciplinar prévia. Essa nova tecnologia não suprime a técnica disciplinar simplesmente porque é de outro nível, está noutra escala, tem outra superfície de suporte e é auxiliada por instrumentos totalmente diferentes. (FOUCAULT, 1999, p. 288-289).

\footnotetext{
${ }^{8} \mathrm{O}$ caso do surto do Zika vírus no Brasil é um bom exemplo. Atingindo majoritariamente a classe pobre da região Nordeste do país, o vírus convoca não apenas a denúncia ao descaso das políticas públicas com relação a uma das graves sequelas causada por ele: a microcefalia em nascituros. Contudo, põe em evidência o descaso da gestão pública pelas condições básicas da vida social: falta de saneamento básico, limpeza inadequada dos espaços públicos, condições de habitação irregulares, etc. responsáveis por fornecer condições propícias aos criadouros do mosquito transmissor do Zika vírus.
} 
anunciação e insurreição da diferença surda: contra-ações na biopolítica da educação bilíngue

Por meio dessa tecnologia do poder populacional, em parceria ao poder conferido ao corpo individual, vemos desenvolver uma série de ações que se dirigem ao funcionamento do humano: “as pressões que se exercem sobre a higiene das famílias; os cuidados dispensados às crianças, à escolaridade, etc. Logo, vocês têm mecanismos disciplinares e mecanismos regulamentadores" (FOUCAULT, 1999, p. 300). Se a escola se produz na política da larga escala, na regulamentação, a partir de uma lógica que se aplicará ao corpo, é porque ela está dentro de um padrão normativo e num jogo de saber que lhe confere legitimidade de ação:

cada instante que se indaga pelas condições de saberes que referenciam o campo da educação, ao mesmo tempo, atingem-se as formas pelas quais as regularidades discursivas acabam se naturalizando no seu esteio epistemológico e em suas justificativas empíricas. Ainda mais porque essa atuação se dá, notadamente, no registro das condutas, aliás, no âmbito das empiricidades mais essenciais. (CARVALHO, 2012, p.130)

Aprofundando a questão do biopoder e da biopolítica como processos que se iniciam no final do século XVIII e se intensificam no XIX, Foucault $(1998 ; 1999)$ promove uma análise das consequências do funcionamento do que ele nomeou por racismo de Estado. Neste caso, o racismo de Estado envolve a manutenção do que deve ser perpetuado e dos saberes que devem ser destituídos. Não vivemos mais sob a ação de um poder soberano, detentor das condições de punir e de matar os indivíduos que afetam o corpo do soberano. No campo da vida politizada sob a égide do racismo de Estado, "o velho direito de causar a morte ou deixar viver foi substituído por um poder de causar a vida ou devolver à morte" (FOUCAULT, 1998, p.130). O ponto de inflexão desta mudança sublinha o caráter administrativo das condições pelas quais o poder de governamento de um Estado qualquer opta por causar a vida. O que se ajunta em torno dos condicionantes capazes de assegurar a vida em população inteira passa a ser entendido por raça, desvinculado a sua definição pelo mero vínculo sanguíneo:

\footnotetext{
O racismo se forma nesse ponto (racismo em sua forma moderna, estatal, biologizante): toda uma política de povoamento, da família, do casamento, da educação, da hierarquização social, da propriedade, e uma longa série de intervenções permanentes ao nível do corpo, das condutas, da saúde, da vida quotidiana, receberam então cor e justificação em função da preocupação mítica de proteger a pureza do sangue fazer triunfar a raça (FOUCAULT, 1998, p.140)
} 
Nesse sentido, articulamos a inclusão ligada às estratégias biopolíticas que gestam ações para as populações deficientes, para a educação especial, e no seu bojo, para as pessoas surdas. Em jogo estão políticas públicas tecidas com o intuito de orientar o modo de prática docente, de organizar a sala de instrução permitida e a língua que se deve viver na escola. Sob tal lógica é possível acionar o conceito do racismo de Estado como meio de purificação da raça surda que deve entrar na língua soberana que pode se manter viva, em funcionamento. Lodi (2013) argumenta que esse viés instrumental conferido à Libras é estratégia que mascara o não aceite de sua entrada de fato na escola. Promove-se o discurso da inclusão, no entanto, o surdo se torna um incluso-excludente, está na sala de aula, mas sua língua é destituída de poder, de lugar, de funcionamento. É como se o surdo fosse incluído em uma população alheia a sua condição para remarcar a sua própria invisibilidade social. Na astúcia deste racismo, não basta o surdo não falar como a população falante e ser silenciado, mas é preciso que ele seja absorvido nesta população até se tornar um surdo invisível socialmente. Por isto mesmo, Martins (2008b) denuncia o uso da Libras na educação básica pensada apenas pela presença de intérpretes, sem mudanças estruturais e curriculares. Essa prática folcloriza a língua de sinais fazendo-a um ornamento cultural, um adereço agregado à diversidade da escola inclusiva, contribuindo para a fragilização, tanto na afirmação singular do sujeito surdo, como das próprias lutas surdas.

Mas habituados que somos aos rituais escolares, damo-nos por satisfeitos com o cumprimento da aparente ordem dos casos, ou seja, se há um intérprete na escola forjando a acessibilidade para a formação do surdo, o papel da inclusão estaria cumprido. Assim, o Estado ocupa o seu lugar no cumprimento formal de formar populações inclusivas inteiras, o que não é diferente com o surdo. Mas será que isto seria suficiente para produzir uma formação-surda? É evidente que não. De um lado, porque o surdo milita justamente contra a sua abstração na população administrada pela regra da normopatologização da vida. Neste sentido, a própria surdez é um enunciado vivo de uma insurreição contra as estratégias que a lançam na inviabilidade social. De outro lado, porque o que se intenta na 
formação do surdo é potencializar nele a oportunidade de se valer de uma língua que lhe traga significações, como no caso Nell.

A escola, com efeito, seria um importante lugar para que surdo pudesse viver experiências formativas responsáveis por deslocá-lo dos destinos das mesmas matrizes de saber, de comportamento e de modos de ser, vazando as paredes maciças do padrão hegemônico para a formação surda pela formação ouvinte. No entanto, o que testemunhamos com as propostas atuais, efeito das malhas biopolíticas, é que "tal concepção limita a transformação proposta para a educação de surdos apenas ao plano discursivo e restringe a inclusão à escola, impossibilitando uma ampliação desse conceito a todas as esferas sociais [...]" (LODI, 2013, p. 49). Em outras palavras, aplicando-a uma vez mais ao 'caso Nell', na educação de surdos, a inclusão, na perspectiva instrumental, se coloca como espaço de governamento do corpo surdo por meio da ortodoxia da língua usada (a língua portuguesa, na modalidade oral e agora na escrita), no apagamento do idioma que possibilita a emergência de uma singularidade surda que, por estratégias biopolíticas, não se permite viver, não se possibilita a aparição (LUZ, 2013). Para Luz (2013), “aparição é agir não por pragmatismo, nem por fim

externo. É viver o gesto que possibilita o acontecimento de si, é viver o fim em si próprio, é ser no mundo de modo desprendido" (p. 45) e aprofunda o conceito, "[...] aparecer é estar simbolicamente de pé na presença de Outros" (LUZ, 2013, p.45), com suas diferenças, sem ter que se moldar na língua e no padrão 'idealizado' que vem de grupos majoritários. Essa é a provocação de Nell em nós, a possibilidade de ver outras expressões de vida, outras experiências. A possibilidade de existência em seu idioma único e desafiador; e é nele e por meio dele que Nell promove sua aparição.

\section{A pauta da insurreição surda: diálogos finais}

Mas se me calasse os outros ruídos recomeçariam, aqueles para os quais as palavras me tornaram surdo, ou que realmente cessaram. Mas eu me calo, acontece, não, nunca, nem por um segundo (BECKETT, 2015, p.36) 
Como diálogos finais, trataremos a noção da insurreição que para nós indica a busca por aberturas de outras possibilidades. Conforme Foucault (2004), insurreição não é uma mera resistência, mas uma dupla ação que envolve uma vontade coletiva politicamente afirmada e, com isso, uma vontade de mudança radical em tudo que condiciona a existência. Deste modo, qualquer insurreição emerge como força contrária a todo modelo vigente, promovendo fissuras no espaço do micro-cotidiano. Em nossas análises, a insurreição surda tem esse lugar de perfuração, de incômodo de mobilizações, de grito gestualizado contra a palavra de ordem.

Um bom caso de insurreição pode ser visto em uma escola-polo de educação inclusiva bilíngue de surdos em uma rede municipal do interior do Estado de São Paulo, que tem se aventurado a nadar contra a maré. Gestores e professores aceitaram o desafio de produzir, em parceria com um projeto de pesquisa, sob supervisão e assessoramento de uma pesquisadora da Universidade Federal de São Carlos (UFSCar), algumas mudanças na estrutura de toda a educação básica, do ensino fundamental I e II. O relato aqui se centra nas salas de aula do ensino fundamental $\mathrm{I}, 1^{\circ}$ ao $5^{\circ}$ ano. Nestas salas, a língua de instrução é a Libras, e ao invés de termos um surdo diluído por sala, ou em escolas distintas, apoiado por intérpretes educacionais, funciona uma sala multisseriada com um grupo significativo de surdos. Os docentes têm produzido conhecimentos em Libras na perspectiva bilíngue, não pela instrumentalidade da Libras, mas na constituição de uma língua que produz discurso, que produz saber. Tal modelo é questionado dentro das lógicas das políticas públicas da educação especial na perspectiva da educação inclusiva, uma vez que tal prática seria excludente, isolando os alunos surdos do convívio com os alunos ouvintes.

Professores, gestores, entre eles professores surdos, que trabalham neste projeto atestam que não há exclusão, há interação entre surdos e ouvintes, prevalecendo um ensino direcionado às demandas surdas. Neste caso, demanda por aquisição de uma língua que só se faz na troca com outros falantes, outros surdos. Essa sala faz parte da escola, não é um apêndice e a quantidade significativa de surdos promove um deslocamento de práticas: na relação com a 
cozinheira que ao ver muitas mãos em movimento testemunha a convocação da aprendizagem da língua de sinais; nos questionamentos que os alunos surdos fazem da ampliação do uso da Libras em outros espaços da escola para interagir com os colegas ouvintes, direção. Ao valorizar o uso da Libras na sala multisseriada querem o mesmo acolhimento na escola. E mais, nas relações com os amigos ouvintes, em momentos específicos passam a respeitar a diferença de espaço de aprendizagem por justificativas linguísticas. Enfim, emanam processos de aparições que são velados quando se mantem um único surdo isolado numa escola composta por uma população ouvinte que apaga suas demandas, inibe seus sinais, minora a potência de toda a sua singularidade.

Esse caso remarca e tipifica muito bem as lutas contra os padrões existentes na formação de populações inclusivas nas escolas. Mais do que isso, coloca em evidência a possibilidade de mudança nos modelos políticos propostos como ideais para a inclusão dos alunos surdos pela ação de intérpretes, no lugar de docentes bilíngues, surdos ou ouvintes. Docente e gestores comentam dos revides sofridos nesses espaços diariamente, indicando o fechamento dessas "salas transgressoras". No entanto, há a atualização de saberes surdos que se articulam e revidam a sua manutenção, fortalecendo a petição da escuta surda e a sua entrada na cena escolar. Tais espaços podem ser pensados pelo conceito de heterotopia de Michel Foucault, como sendo a produção de espaços outros dentro de um mesmo espaço. Suas análises referem-se à transposição de sentidos de usos espaciais por crianças, como a cama dos pais que pode servir de espaço do lúdico, para além da função social que lhe é atribuída, ou melhor, da função cultural (espaço de dormir) dada a ela. Ora, a própria insurreição surda mobiliza a vontade de outros lugares para o surdo poder fazer valer a sua condição, a sua fala-língua, o seu corpo, o seu gestual, o seu modo de ser, para além dos lugares sociais que a biopolítica intenta limitá-lo. Seria preciso, assim, permitir que a surdez se constitua como uma experiência em “seus próprios contra-espaços [...]” (FOUCAULT, 2013, p. 20). É para isto que a surdez milita; é para isto que ela se insurge, exigindo de dentro da homonomia sócio-histórica a contra-afirmação de uma heteronomia feita em carne e osso. 
A inclusão pode ser tomada como contraespaço ou uma heterotopia surda capaz de promover uma experiência com a educação de outra maneira e com outras referências, a partir da escola que temos. Teríamos, assim, condições para repensarmos as estratégias inclusivas que ainda ecoam a normalização da biopolítica, lançando os surdos na identidade populacional para a qual não cessam de se insurgir. Encontra-se em jogo não apenas uma forma de luta capaz de produzir outros saberes, afrontando o constante embate por experiências surdas no 'ensurdecimento' apresentado pelas políticas públicas atuais que pensam a educação inclusiva e paralisam a educação bilíngue sob o efeito redutor da presença da Libras. Ao cabo, o mundo da surdez atiça na memória cega-surda de nossas matrizes de experiência a lancinante anunciação e a insurreição de sua própria singularidade e diferença, em nome de toda contra-ação capaz de fazer sangrar a biopolítica da educação bilíngue que não ousa insurgir contra si mesma.

\section{Referências}

BASTOS, Edinalda Rosa Oliveira. Experiências culturais de alunos surdos em contextos socioeducacionais: o que é revelado? Tese de doutorado. Programa de Educação da Universidade Federal da Bahia. Salvador, 2013.

BECKETT, Samuel. Textos para nada. São Paulo: CosacNaify, 2015.

CARVALHO, Alexandre Filordi de. Foucault e a potência normativa do saber no campo da educação. Revista ETD. Educação Temática Digital, v. 14, 2012, p. 121140.

CARVALHO, Alexandre Filordi de. Por uma ontologia política da (d)eficiência no governo da infância. In: Haroldo de Resende (Org.). Michel Foucault: o governo da infância. Belo Horizonte: Autêntica, 2015, v. 1, p. 25-47.

CARVALHO, Daniel Junqueira. Não basta ser surdo para ser professor: as práticas que constituem o ser professor surdo no espaço da inclusão. Dissertação de mestrado defendida no programa de pós-graduação em educação. Universidade Federal do Espírito Santo (UFES). Vitória, 2016.

CÉSAR, América; CAVALCANTI, Marilda do Couto. Do singular para o multifacetado: o conceito de língua como caleidoscópio. In: CAVALCANTI, M.C; BORTONI-RICARDO, S.M. (ORGS.). Transculturalidade, linguagem e educação. Campinas, SP. Mercado de Letras, 2007.

FOUCAULT, Michel. What is critique. In. SCHMIDT, James. What is enlightenment? Los Angeles/London: University of California Press, 1996. FOUCAULT, Michel. Microfísica do Poder. Trad. de Roberto Machado. Rio de Janeiro: Graal, 1979. 
anunciação e insurreição da diferença surda: contra-ações na biopolítica da educação bilíngue

FOUCAULT, Michel. História da sexualidade 1: a vontade de saber. 13. ed. Rio de Janeiro: Graal, 1998.

FOUCAULT, Michel. Em defesa da sociedade: Curso no Collège de France (19751976). Trad. de Maria Ermantina Galvão. São Paulo: Martins Fontes, 1999.

FOUCAULT, Michel. L'espri d'un monde sans esprit. In. Dits et Écrits III (19761979). Gallimard: Paris, 2004, p.743-755.

FOUCAULT, Michel. O governo de si e dos outros. Curso no Collège de France (19821983). São Paulo: Editora WMF Martins Fontes, 2010.

FOUCAULT, Michel. A coragem da verdade: o governo de si e dos outros II. Curso no Collège de France (1983-1984). São Paulo: Editora WMF Martins Fontes, 2011a. FOUCAULT, Michel. Do Governo dos Vivos (excertos do Curso no Collège de France 1979-1980). Organizado por Nildo Avelino. São Paulo: Centro de Cultura Social; Rio de Janeiro: Achiamé, 2011b.

FOUCAULT, Michel. O Corpo Utópico e as Heterotopias. São Paulo: N-1 Edições, 2013.

GESSER, Audrei. Um olho no professor surdo e outro na caneta: ouvintes aprendendo a língua de sinais. Tese de doutorado defendida na Universidade Estadual de Campinas, no instituto de estudos da linguagem, 2006.

Disponível em: http:/ /libdigi.unicamp.br/document/?code=vtls000379600 Acesso em: 10/02/2016.

GESSER, Audrei. Libras: Que língua é essa? Crenças e preconceitos em torno da língua de sinais e da realidade surda. São Paulo: Parábola Editorial, 2009.

LIPOVETSKY, Gilles. A sociedade pós-moralista: o crepúsculo do dever e a ética indolor dos novos tempos democráticos. São Paulo: Manole, 2005.

LODI, A.C.B. Educação bilíngue para surdos e inclusão segundo a Política Nacional de Educação Especial e o Decreto $n^{\circ}$ 5.626/05. Educação e Pesquisa (USP. Impresso), v. 39, p. 49-63, 2013.

LOPES, Maura Corcini. Surdez e educação. Belo Horizonte: Autêntica, 2007.

MAHER, Terezinha Machado. Do casulo ao movimento: a suspensão das certezas na educação bilíngue e intercultural. IN: CAVALCANTI, M.C; BORTONIRICARDO, S.M. (ORGS.). Transculturalidade, linguagem e educação. Campinas, SP. Mercado de Letras, 2007.

MARTINS, Vanessa Redina de Oliveira. Educação de surdos no paradoxo da inclusão com intérprete de lingua de sinais: Relações de poder e (re) criações do sujeito.

Dissertação de Mestrado. Faculdade de Educação da Universidade Estadual de Campinas. UNICAMP, Campinas/SP, 2008a.

MARTINS, Vanessa Regina de Oliveira. Análise das vantagens e desvantagens da Libras como disciplina curricular no ensino Superior. Rev. Cad. CEOM, v.21, n.28, p.191-206, 2008b.

MARTINS, Vanessa Regina de Oliveira. Posição-mestre: desdobramentos foucaultianos sobre a relação de ensino do intérprete de língua de sinais educacional. Tese de doutorado defendida na Faculdade de Educação da Universidade Estadual de Campinas. UNICAMP, Campinas/SP, 2013a. 
MARTINS, Vanessa Regina de Oliveira. Resistências-sinalizadas: o cuidado de si como possibilidade de diferenças surdas. In: Fermentario N.7. Instituto de Educación, Facultad de Humanidades y Ciencias de la Educación, Universidad de la República. Montevideo, 2013 b.

MORGENSTERN, Juliane Marshall; WITCHS, Pedro Henrique. Práticas de si na produção de subjetividades surdas brasileiras. IN: ANPED. Apresentação em comunicação oral. Pesquisa financiada pela Capes. Florianópolis, 2015.

REZENDE, Patrícia Luiza Ferreira. Implante coclear na constituição dos sujeitos surdos. Tese de doutorado apresentada no centro de ciências da educação. Programa de pós-graduação em educação. Florianópolis/ SC, 2010. SKLIAR, Carlos. A surdez: um olhar sobre as diferenças. Porto Alegre: mediação, 2013.

SOUZA, Regina Maria de. Língua de Sinais e Escola: Consideração a partir do texto de regulamentação da língua brasileira de sinais. In: ETD (Educação Temática Digital): Educação dos surdos e língua de sinais. V.7 n.2, 2006. pp. 263278. Disponível em:

http:/ / 143.106.58.55/revista/viewarticle.php?id=127\&layout=abstract. Acesso em: 02/04/2016

STROBEL, Karin. As imagens do outro sobre a cultura surda. Florianópolis: Ed. Da UFSC, 2008.

\section{Filmografia}

APTED, Michael. Nell. U.S.A. 1994.

Recebido em: 25.05.2016

Aceito em: 01.06.2016

\footnotetext{
I Fundação de Amparo à Pesquisa do Estado de São Paulo - FAPESP - Processos: 16/05440-7 e 15/09357-4.

" Vanessa Regina de Oliveira Martins - Doutora em Educação pela UNICAMP. Docente do departamento de psicologia da Universidade federal de São Carlos UFSCar. Pesquisa com financiamento pela Fundação de Amparo a Pesquisa do Estado de São Paulo (FAPESP ) Processo no 2015/09357-4.
} 